\title{
Experimental Philosophy of Pain
}

Justin Sytsma and Kevin Reuter

\begin{abstract}
The standard view of pains among philosophers today is that their existence consists in being experienced. The typical line of support offered for this view is that it corresponds with the ordinary or commonsense conception of pain. Despite this, a growing body of evidence from experimental philosophers indicates that the ordinary understanding of pain stands in contrast to the standard view among philosophers. In this paper, we will survey this literature and add to it, detailing the results of seven new studies on the ordinary understanding of pain using both questionnaire and corpus analysis methods.
\end{abstract}

The standard view among philosophers today is that pains are mental states, and specifically that pains are phenomenally conscious mental states. Although researchers are not in complete agreement about how to understand the concept of phenomenal consciousness, the standard idea is that a being is phenomenally conscious if that being has phenomenally conscious mental states, and that a mental state is phenomenally conscious just in case there is "something it is like" (Nagel 1974) to be in that state, where this vague phrase is understood to mean that the state has phenomenal qualities. With regards to pains, the idea is that what makes a state a pain is the way it feels to the being experiencing it. As such, on the standard view there is no appearance-reality distinction to be drawn for pains. To have the appearance of pain (the phenomenal experience of pain) is for there to be a pain, and vice versa.

Should we accept the standard view? The primary reasons that philosophers have offered for this view rest not so much on explicit philosophical arguments or empirical data, but rather on appeals to intuitions. Sometimes this is asserted directly. For example, David Lewis (1980, 222) writes: "Pain is a feeling. Surely that is uncontroversial." Other times, philosophers claim that commonsense verdicts about problematic cases are best explained by the thesis that the folk 
conception of pain is a mental state view. We will focus on three problem cases in this articlethe possibility of shared pains, unfelt pains, and pain hallucinations.

According to the standard view, pains are necessarily private, such that there can be no shared pains. And this is often taken to reflect the commonsense view of pains. For example, Michael Tye $(2005,100)$ asserts that the folk conception of pain denies the possibility of shared pains, and explains this in terms of the folk conception treating pains as phenomenally conscious mental states:

You cannot feel my pains and I cannot feel yours. Even if we are Siamese twins, joined at the hip and stung there by a bee, intuitively there are two pains, yours and mine....

That pains are necessarily private... is part of our folk conception of pain and it requires explanation. The obvious explanation is that pain is a feeling or an experience of a certain sort. That is certainly how scientists think of pain.... And it is also part of our commonsense conception.

Similar claims are made about the possibility of unfelt pains. For instance, Murat Aydede (2005a, $\mathrm{x}$ ) claims that "it is part of the commonsense conception of pains... that they can't exist without someone's feeling them." He goes on to contend that "there is an air of paradox when someone talks about unfelt pains," claiming that "one is naturally tempted to say that if a pain is not being felt by its owner then it does not exist" $(2005 \mathrm{~b}, 4) .{ }^{1}$ Such observations are taken to support the claim that the commonsense conception of pain treats pains as mental states rather than bodily states. Thus, Aydede $(2009,4-5)$ writes that "common sense... resists identifying a pain with any physical feature or condition instantiated in the body," asserting that "a quick thought experiment should confirm this":

Suppose that we do in fact attribute a physical condition, call it $P C$, when we attribute pain to body parts, and that $P C$ is the perceptual object of such experiences. So, for instance, John's current excruciating experience (call this $E$ ) is caused by and represents a physical condition in his right thigh and our ordinary concept of pain applies in the first

\footnotetext{
${ }^{1}$ See Reuter and Sytsma (ms) for further examples and an extended discussion, as well as Reuter (2016) for a critical challenge to the idea that the standard view can be squared with data from developmental studies.
} 
instance to this condition in his thigh. From this it would follow that... John would have pain if he had $P C$ but no $E$ (as would be the case, for instance, if he had taken absolutely effective painkillers or his thigh had been anesthetized). (2009, 4-5)

Aydede then charges that this conclusion is "intuitively incorrect," writing that it "appear[s] to clash with our ordinary or dominant concept of pain" (5).

Somewhat more controversially, some philosophers have asserted that commonsense denies the possibility of pain hallucinations. For example, Ned Block $(2005,138)$ writes that pretheoretically "we do not acknowledge pain hallucinations, cases where it seems that I have a pain when in fact there is no pain." And, again, this can be explained in terms of the commonsense conception corresponding with the standard view of pains. The standard view asserts that to feel a pain is to have a pain (and vice versa), leaving no room for pain hallucinations - for cases in which one feels a pain without actually having a pain. As Hilary Putnam $(1963,218)$ writes, “one cannot have a 'pain hallucination'... simply because any situation that a person cannot discriminate from a situation in which he himself has a pain counts as a situation in which he has pain."2

But are these claims correct? Is it true that the commonsense conception of pain corresponds with the standard view in philosophy? And is it true that commonsense denies the possibility of shared pains, unfelt pains, and pain hallucinations $?^{3}$ A growing body of literature in experimental philosophy has attempted to test these claims. ${ }^{4}$ And the results suggest that the commonsense conception of pain is quite different from the standard view. Not only do the

\footnotetext{
${ }^{2}$ See Reuter, Phillips, and Sytsma (2014) for further examples and an extended discussion.

${ }^{3}$ If this is correct, a further issue arises: Should we accept the deliverances of our intuitions with regard to the nature of pain? And to what extent should we treat these deliverances as being defeasible and open to revision in the light of theoretical considerations and/or empirical findings?

${ }^{4}$ For a brief introduction to experimental philosophy see Sytsma and Machery (2013). For extended introductions see Alexander (2012) and Sytsma and Livengood (2015). For collections of articles see Knobe and Nichols (2008, 2013), as well as the volumes in the Advances in Experimental Philosophy series. For discussions of some recent disputes see Machery and O'Neil (2014) and Sytsma (forthcoming). And for an extensive survey of the state of the art of experimental philosophy see Sytsma and Buckwalter (2016).
} 
findings indicate that lay people tend to accept the possibility of shared pains, unfelt pains, and pain hallucinations, but they suggest that they do so because they are not conceiving of pains as mental states but are instead conceiving of them as bodily states. In this article, we will both survey the empirical work that has been done to date and expand on it. In the first section, we survey a wide range of studies using questionnaire methods, in addition to presenting the results of six new studies on judgments about the possibility of unfelt pains and pain hallucinations. In the second section, we discuss the corpus analysis conducted by Reuter (2011) on the use of pain terms in English, then extend this to the use of pain terms in German.

\section{Questionnaire Studies of Pain Judgments}

Most of the work that has been done on the commonsense conception of pain has employed questionnaires to elicit pain judgments. While questionnaire methods might be thought to be restricted to descriptive studies, these studies also include experiments and quasi-experiments. ${ }^{5}$ The most common set-up for questionnaire studies investigating the commonsense conception of pain is to present a set of participants with one of a series of short stories or thought-experiments (the vignette) followed by one or more questions about it. In this section, we'll survey some of the work that has been done on the commonsense conception of pain using questionnaire methods, in addition to presenting the results of six new studies expanding on these results.

\subsection{Studies on the Concept of Phenomenal Consciousness}

Questionnaire studies on the commonsense conception of pain grew out of more general work in experimental philosophy of mind investigating how people understand and attribute those mental

\footnotetext{
${ }^{5}$ For a discussion of the difference between experiments, quasi-experiments, and descriptive studies see Sytsma and Livengood (2015, Chapter 5).
} 
states that philosophers typically treat as being phenomenally conscious. ${ }^{6}$ Building on the methodological work in Sytsma and Machery (2009) responding to Knobe and Prinz (2008), Sytsma and Machery (2010) argue that lay people by and large do not employ the concept of phenomenal consciousness. If they are correct, then we would also expect the commonsense conception of pain to diverge significantly from the standard view amongst philosophers, since philosophers have generally taken pains to be phenomenally conscious mental states.

Most importantly, Sytsma and Machery present evidence that, in contrast to philosophers, lay people treat two prototypical examples of phenomenally conscious mental states—seeing red and feeling pain — differently. They gave participants either a description of a normal human or a simple non-humanoid robot performing behaviorally analogous tasks expected to elicit attributions of these mental states for the human. Sytsma and Machery found that while lay people tended to attribute seeing red to the robot but not feeling pain, philosophers tended to deny that the robot either saw red or felt pain. ${ }^{7}$ Based on these results they argue that if lay people were employing the concept of phenomenal consciousness in responding to these questions, then they should have treated seeing red and feeling pain similarly, denying that the simple robot was in either state- just as the philosophers did. But they did not, suggesting that they were not employing the concept of phenomenal consciousness.

Building on these results, in addition to the arguments put forward in Sytsma (2009) and Sytsma (2010c), Sytsma (2012) hypothesized that the pattern of responses that Sytsma and Machery found for lay people reflects that they by and large hold a naïve view of colors and

\footnotetext{
${ }^{6}$ For a recent survey, see Sytsma (2014a). For a short introduction to work in experimental philosophy of mind, see Machery and Sytsma (2011). For a more extended review, see Sytsma (2010a) and Sytsma and Livengood (2015). For a collection of cutting-edge articles, see Sytsma (2014b), as well as the section on "Philosophy of Mind" in Sytsma and Buckwalter (2016).

${ }^{7}$ These results have been replicated a number of times; see Sytsma and Machery (2012), Sytsma (2012), Sytsma (2014c).
} 
pains - that is that rather than treat colors or pains as qualities of mental states, they conceive of them as qualities of objects outside the mind/brain. The basic idea is that people tend to deny that the robot feels pain because they conceive of pains as being instantiated in injured body parts, but doubt that the robot has the right sort of body parts to support pains. On this view, while soft and fleshy body parts can support pains, hard and metallic body parts cannot. Sytsma tested this hypothesis by giving participants one of a pair of vignettes in which a woman lost her hand in an accident and had it replaced with either a hard and metallic robotic hand or a soft and fleshy bioengineered hand. The result was that participants were significantly more likely to attribute feeling pain to the woman when her hand was replaced with the bioengineered hand than the robotic hand. In contrast, when the woman instead lost her eyes in an accident and had them replaced with either robotic eyes or bioengineered eyes, the type of replacement eye had no effect on attributions of seeing red.

In a related series of studies, Sytsma (2010b) explored the commonsense conception of colors, arguing that the results indicated that people hold a naïve view. He then extended this to look at the commonsense conception of pain. He began by giving lay people a vignette describing both the standard view in philosophy that pains are mental states and the contrasting view that pains are bodily states, then asked them a series of questions about how they understand pain. Sytsma found that most of the participants denied that pains are mental states and endorsed that they are bodily states. Further, in opposition to the standard philosophical view, the majority endorsed the possibility of unfelt pains, as one would expect if pains are being conceived of as bodily states. The claim that the lay conception of pains allows for unfelt pains found additional support in two further studies involving variations on a vignette in which an 
injured man was distracted from a severe pain. In line with the previous study, Sytsma found that a majority of participants in each case treated this as an example of an unfelt pain.

In another set of studies, Sytsma (2010b) tested the claim that commonsense denies the possibility of shared pains, giving participants vignettes in which two individuals shared the same injured body part. In such cases, the standard philosophical view says that there are two different pains (two different brains meaning two different mental states) while the bodily conception of pains says that there is just one pain (there is only one injured body part). Most notably, Sytsma asked participants in a classroom setting about a pair of conjoined twins sharing the lower half of their body who stub their shared toe. Against the standard view, and the explicit claim from Tye $(2005,100)$ noted above, a majority of Sytsma's participants answered that the twins felt one and the same pain when they stubbed their toe. ${ }^{8}$

\subsection{New Studies using Conjoined Twins Vignettes}

We ran three new studies expanding on Sytsma's (2010b) study involving conjoined twins. In addition to replicating Sytsma's results for shared pains, we adjusted the vignette to explore the issue of unfelt pain. We hypothesized that if one of the two conjoined twins were given a painkiller and showed no pain response, while the other twin continued to exhibit an ordinary pain response, people would tend to hold that the pain continued even though the first twin didn't feel it.

In our first study, we gave people both a modified version of Sytsma's original probe as well as a new probe where one twin is given a painkiller. The two probes were presented on

\footnotetext{
${ }^{8}$ Participants were asked whether the twins felt one and the same pain or two different pains, and answered on a 7point scale anchored at 1 with "clearly same pain," at 4 with "not sure," and at 7 with "clearly different pains." The mean response was 3.29, which was significantly below the neutral response of 4 .
} 
separate pages and the order of the two pages was randomized. Participants were not able to go

back after responding to a probe. The shared pain vignette reads as follows:

Bobby and Robby are conjoined twins that are joined at the torso. While they are distinct people, each with their own beliefs and desires, they share the lower half of their body. One day while running through a park they forcefully kicked a large rock that, unbeknownst to them, was hidden in the grass. Bobby and Robby both grimaced and shouted out 'Ouch!'

Participants were then asked the following two questions, answering the first by selecting either "one and the same pain" or "two different pains" and the second by selecting either "yes" or "no":

(1) Did Bobby and Robby feel one and the same pain or two different pains when they kicked the rock?

(2) Did Bobby and Robby kick a large rock?

The painkiller vignette reads as follows:

Johnny and Tommy are conjoined twins that are joined at the torso. While they are distinct people, each with their own beliefs and desires, they share the lower half of their body. One day they accidentally dropped a heavy weight on their left foot. Johnny and Tommy both grimaced and shouted out 'Ouch!' They were then rushed to the hospital for treatment. Unfortunately, the nurse who checked them in was unfamiliar with conjoined twins. As a result, Johnny was given a pill for the pain while Tommy was left untreated. Ten minutes later, the doctor arrived to examine them. When she pushed on the injured foot, Tommy grimaced and shouted out 'Ouch!' while Johnny merely shrugged his shoulders and said it didn't hurt at all.

Participants were then asked which of following two claims best reflected their view about this scenario, with the answer choices counterbalanced for order:

(a) There was a pain in Johnny and Tommy's injured foot when the doctor pushed on it: While Tommy felt the pain in their foot, the painkiller prevented Johnny from feeling that pain.

(b) There was not a pain in Johnny and Tommy's injured foot when the doctor pushed on it: While the foot caused Tommy to feel pain, the painkiller prevented Johnny from feeling pain. 
In addition, participants were given a comprehension check—Did Johnny and Tommy drop a heavy weight on their left foot?-which they answered by selecting either "yes" or "no."

Responses to these two probes were collected online from 335 native English speakers, 16 years of age or older, with at most minimal training in philosophy. ${ }^{9}$ The results are shown in Figure 1 below. The first thing to note is that we replicated the basic finding about shared pains from Sytsma (2010b), with $68.5 \%$ (217/317) of the participants who got the comprehension check correct answering that the conjoined twins felt one and the same pain. ${ }^{10}$ This was significantly above $50 \% .{ }^{11}$ We got an even stronger result for the painkiller probe, with $83.7 \%$ $(251 / 300)$ of the participants who got the comprehension check correct answering that there was a pain in the shared foot that the second twin did not feel. ${ }^{12}$ Again, this was significantly above $50 \% .{ }^{13}$ These results suggest that the commonsense conception of pain is at odds with the standard view in philosophy: first, we find that people tend to allow for shared pains, seemingly treating pains in conjoined twin cases as being located in the body and felt by both individuals, which indicates that they are not thought of as being in the mind/brain; second, we find that

\footnotetext{
${ }^{9}$ Responses were collected through the Philosophical Personality website (http://philosophicalpersonality.com). Participants were counted as having more than minimal training in philosophy if they were philosophy majors, had completed a degree with a major in philosophy, or had taken graduate-level courses in philosophy. The participants were $71.6 \%$ women, with an average age of 35.0 years, and ranging in age from 16 to 86 .

${ }_{10} 18$ participants missed the comprehension check and were removed, although this had minimal effect on the results: including those participants, $67.5 \%$ (226/335) answered that the twins felt one and the same pain. Further, we saw no notable difference in responses based on the order in which they saw the probes: of those who got the comprehension check correct, $69.8 \%$ (90/129) of participants who got the shared pain probe first answered that the twins felt one and the same pain compared to $67.6 \%$ (127/188) of participants giving that answer when they got the painkiller probe first.

${ }_{11}^{2}(1, \mathrm{~N}=317)=42.4479, \mathrm{p}<0.001$, one-tailed

1235 participants missed the comprehension check and were removed from the analysis, although this had minimal effect on the results: including those participants, 82.1\% (275/335) selected the (a) answer. Again, there was no notable difference in responses based on the order in which they saw the probes: of those who got the comprehension check correct, $84.3 \% \%(102 / 121)$ of participants who got the shared pain probe first gave the (a) answer compared to $83.2 \%(149 / 179)$ of participants giving that answer when they got the painkiller probe first. ${ }^{13} \chi^{2}(1, \mathrm{~N}=300)=134.67, \mathrm{p}<0.001$, one-tailed
} 
people tend to hold that the ability to feel an ongoing pain can be blocked, which indicates that they allow for the occurrence of unfelt pains.

It might be objected that perhaps participants were taking the answer choices figuratively and that they don't literally think that there is a pain in the injured foot. To check this possibility, we began by rewriting the answer choices for the painkiller probe to emphasize that we were concerned with the actuality of the pain:

(a) There actually is a pain in the injured foot: while Tommy feels the pain in the foot, the painkiller prevents Johnny from feeling that pain.

(b) There is not actually a pain in the injured foot: while the foot causes Tommy to have the feeling of there being a pain in the foot, the painkiller prevents the foot from causing Johnny to have such a feeling.

Responses were collected from 149 participants using the same website and restrictions as the previous study.${ }^{14}$ Answer choices were counterbalanced for order and the question was followed by the same comprehension check used in the painkiller probe in our first study. The results are shown in Figure 1 below. The results for Study 2 closely match those from Study 1, with 84.0\% $(110 / 131)$ of participants who got the comprehension check correct answering that there was a pain in the shared foot that the second twin did not feel. ${ }^{15}$ Again, this was significantly above $50 \%{ }^{16}$

To further address the objection, in our third study we rewrote the answer choices to further emphasize that they should be read literally:

(a) While Tommy felt the pain in their foot, the painkiller prevented Johnny from feeling that pain. The pain is literally in Johnny and Tommy's injured foot.

\footnotetext{
14 The participants were $73.2 \%$ women, with an average age of 37.2 years, and ranging in age from 16 to 76 .

1516 participants missed the comprehension check and were removed from the analysis, although this had minimal effect on the results: including those participants, $84.6 \%(126 / 149)$ selected the (a) answer.

${ }^{16} \chi^{2}(1, \mathrm{~N}=131)=59.115, \mathrm{p}<0.001$, one-tailed
} 
(b) While the foot caused Tommy to feel a pain, the painkiller prevented Johnny from feeling any pain. However, the pain is not literally in Johnny and Tommy's injured foot.

Responses were collected from 178 participants, again using the same website and restrictions as the previous studies. ${ }^{17}$ Again, the answer choices were counterbalanced for order and the question was followed by the comprehension check question. The results are shown in Figure 1. The results were somewhat lower than for the previous wordings, with $65.7 \%(109 / 166)$ of participants giving the (a) answer. ${ }^{18}$ Despite this drop, however, the percentage remained significantly above the 50\% mark, again indicating that native English-speakers tend to hold a conception of pains that allows for the occurrence of unfelt pains. ${ }^{19}$

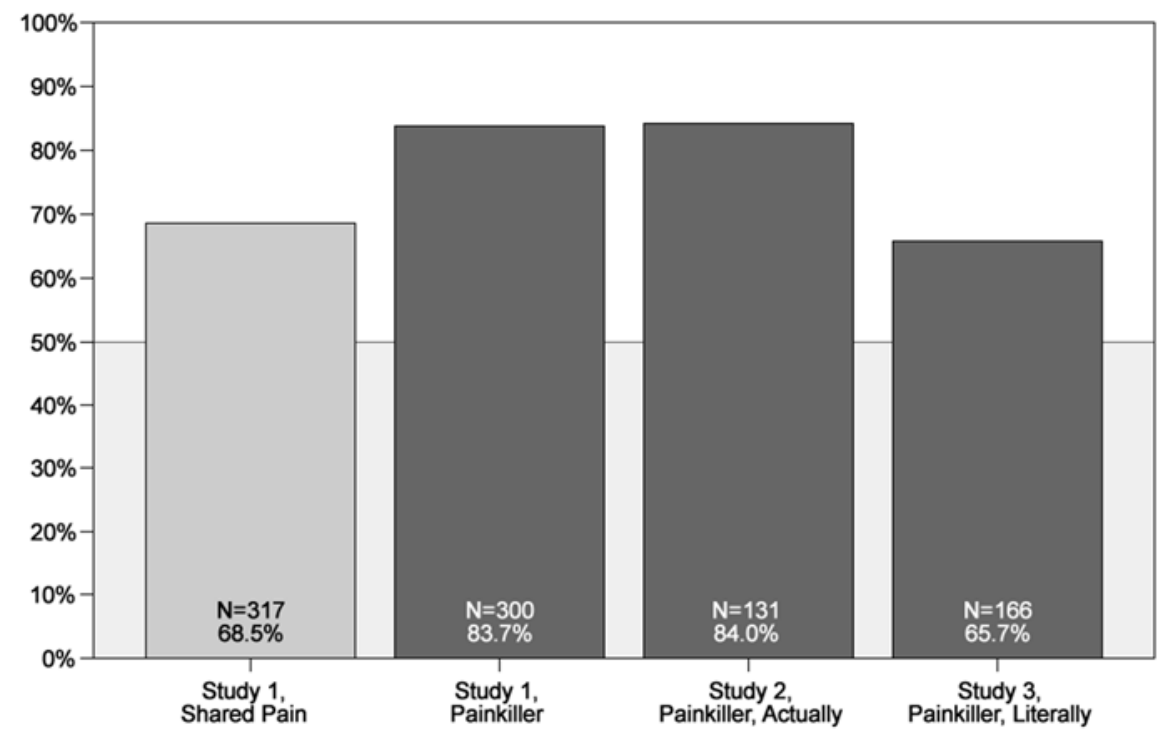

Figure 1: Results for Studies 1, 2, and 3 (restricted to participants who correctly answered the comprehension check).

\footnotetext{
${ }^{17}$ The participants were $65.2 \%$ women, with an average age of 33.7 years, and ranging in age from 16 to 100 .

${ }_{18} 12$ participants missed the comprehension check and were removed from the analysis, although this had minimal effect on the results: including those participants, $65.2 \%$ (116/178) selected the (a) answer.

${ }^{19} \chi^{2}(1, \mathrm{~N}=166)=15.6687, \mathrm{p}<0.001$, one-tailed
} 


\subsection{Studies Focusing on the Commonsense Conception of Pain}

The literature we've surveyed so far has concerned the broader project understanding ordinary attributions of mental states and whether lay people tend to employ the concept of phenomenal consciousness. The commonsense conception of pain is interesting in its own right, however, outside of how this intersects with the consciousness debates in philosophy of mind. And a number of recent papers have employed questionnaire methods with the specific aim of testing the commonsense conception of pain.

In a series of studies, Reuter, Phillips, and Sytsma (2014) investigated the claim that the commonsense conception of pain denies the possibility of pain hallucinations and pain illusions. Contrary to what one might expect if the commonsense conception of pain corresponds with the standard view, Reuter and colleagues found that a majority of participants answered "yes, it is possible" when asked whether a particular pain might merely be a pain hallucination. One possible worry is that lay people could be operating with a definition of "hallucination" that diverges from that assumed by philosophers. To test this, Reuter et al. asked participants to describe how they understand the term "hallucination." They were then asked the following three statements, counterbalanced for order, answering each using a 7-point Likert scale anchored at 1 with "Strongly Disagree," at 4 with "Neutral," and at 7 with "Strongly Agree":

(1) It is possible for someone to have a hallucination of a throbbing pain.

(2) It is possible for someone to have a hallucination of a demonic voice.

(3) It is possible for someone to have a hallucination of a pink elephant.

Reuter and colleagues found that not only were the descriptions participants gave for how they understand "hallucination" in line with those found in the philosophical literature, but that participants were significantly more likely to agree with the pain hallucination statement than to disagree (the mean response was 4.96). 
In another study, Reuter et al. shifted to questions about pain illusions rather than hallucinations. They found that a majority of participants affirmed that it was possible to have a range of pain illusions. For instance, $83.3 \%$ of participants responded "yes, it is possible" when asked "Do you think that it is possible to feel a pain as being less intense than it really is?" while $70.6 \%$ gave that response when asked "Do you think that it is possible to feel a pain as being in your ankle even though it is really in your foot?"

\subsubsection{New Studies on Pain Hallucinations and Pain Illusions}

We ran three new studies extending Reuter et al.'s (2014) work on pain hallucinations. In Study

4, we repeated the study described above but removed the question asking participants to describe how they understand the term "hallucination." Participants were presented with the same three questions shown above, counterbalanced for order, using the same 7-point Likert scale. Responses were collected from 110 participants, again using the same website and restrictions as the previous studies. ${ }^{20}$ The results are shown in Figure 2 below. In line with Reuter et al.'s (2014) results, we found that participants were more likely to agree with the pain hallucination statement than to disagree. The mean response was 5.03, which was higher than for either the auditory hallucination question (4.95) or the visual hallucination question (4.50). The mean for each question was significantly above the neutral point. ${ }^{21}$ Further, the modal response for the pain hallucination question was 7 (30/110), with only $19.1 \%(21 / 110)$ of participants registering disagreement by selecting an answer of 1,2 , or 3 compared to $67.3 \%(74 / 110)$ of participants registering agreement by giving an answer of 5,6 , or 7 .

\footnotetext{
20 The participants were $73.6 \%$ women, with an average age of 41.9 years, and ranging in age from 16 to 85 . ${ }^{21}$ (1) $\mathrm{t}(109)=5.9374, \mathrm{p}<0.001$, one-tailed; (2) $\mathrm{t}(109)=5.4726, \mathrm{p}<0.001$, one-tailed; (3) $\mathrm{t}(109)=2.4399$, $\mathrm{p}=0.008$, onetailed.
} 
In Study 5, we again repeated Reuter et al.'s study, but this time first provided participants with the following statement defining "hallucination" before they answered the questions:

The most common type of hallucination is auditory hallucinations. In having an auditory hallucination, a person thinks that she hears something, such as a voice, when there is no relevant auditory stimulus in her immediate vicinity (for example, when there is nobody around her who is speaking). It is often thought that although it is as if the person hears a voice, the person undergoing the hallucination does not actually hear a voice. Because she does not actually hear a voice, the episode is characterized as a hallucination: If she were to hear a voice, then the episode would not count as a hallucination.

Once again, we asked participants the same three questions, counterbalanced for order, using the same 7-point Likert scale. Responses were collected from 103 participants, using the same website and restrictions as the previous studies. ${ }^{22}$ The results are shown in Figure 2. Again, we found that participants were more likely to agree with the pain hallucination statement than to disagree. The mean response was 4.43 , which was higher than for the visual question (4.35) and slightly lower than for the auditory question (4.70). The means for the first two questions were significantly above the neutral point, while the mean for the third was borderline significantly above the neutral point. ${ }^{23}$ Further, the modal response for the pain hallucination question was 7 (24/103), with only $28.2 \%$ (29/103) of participants registering disagreement by selecting an answer of 1, 2, or 3 compared to $49.5 \%$ (51/103) of participants registering agreement by giving an answer of 5, 6, or 7 . Notably, the percentage of neutral responses $(22.3 \%, 23 / 103)$ was higher than in Study $4(13.6 \%, 15 / 110)$, suggesting that the definition we provided might have confused some participants, perhaps explaining the slightly lower mean ratings.

\footnotetext{
${ }^{22}$ The participants were $66.0 \%$ women, with an average age of 43.8 years, and ranging in age from 16 to 88 . ${ }^{23}$ (1) $\mathrm{t}(102)=2.1086, \mathrm{p}=0.01871$, one-tailed; (2) $\mathrm{t}(102)=3.4327, \mathrm{p}<0.001$, one-tailed; (3) $\mathrm{t}(102)=1.5629, \mathrm{p}=0.06059$, one-tailed
} 


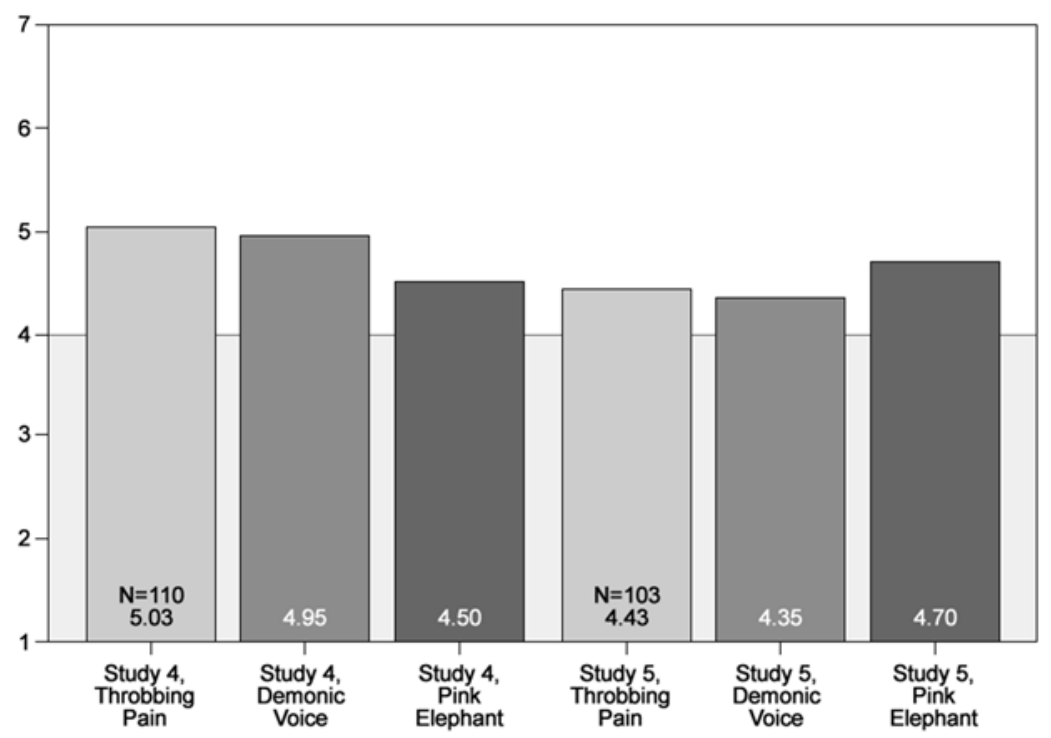

Figure 2: Results for Studies 4 and 5.

In Study 6, we turned to pain illusions. Each participant was asked the following three questions, contrasting a pain episode with two gustatory episodes:

(1) Do you think that it is possible to feel a pain as being hurtful even though it is really not hurtful at all?

(2) Do you think that it is possible that something tastes disgustingly even though it is really not disgusting at all?

(3) Do you think that it is possible that something tastes salty even though it is really not salty at all?

The questions were counterbalanced for order and participants answered each by selecting either "Yes," "No," or "I don’t know." Responses were collected online from 101 participants using Amazon's Mechanical Turk. ${ }^{24}$ Results are shown in Figure 3. The results were in line with the findings of Reuter et al. (2014), with a majority of participants responding "yes" to the pain illusion question $(81.2 \%, 82 / 101)$, with similar responses being given for each of the gustatory

\footnotetext{
${ }^{24}$ The participants were $35.6 \%$ women, with an average age of 29.2 years, and ranging in age from 18 to 74 . All participants were reimbursed for their participation.
} 
cases $\left(83.2 \%, 84 / 101\right.$ and $72.3 \%, 73 / 101$ respectively). ${ }^{25}$ Together, these three studies lend further support to the claim that the commonsense conception of pain diverges from what has standardly been assumed by philosophers. It appears that pace the claim of many philosophers, the commonsense conception of pain allows for the occurrence of pain hallucinations as well as pain illusions.

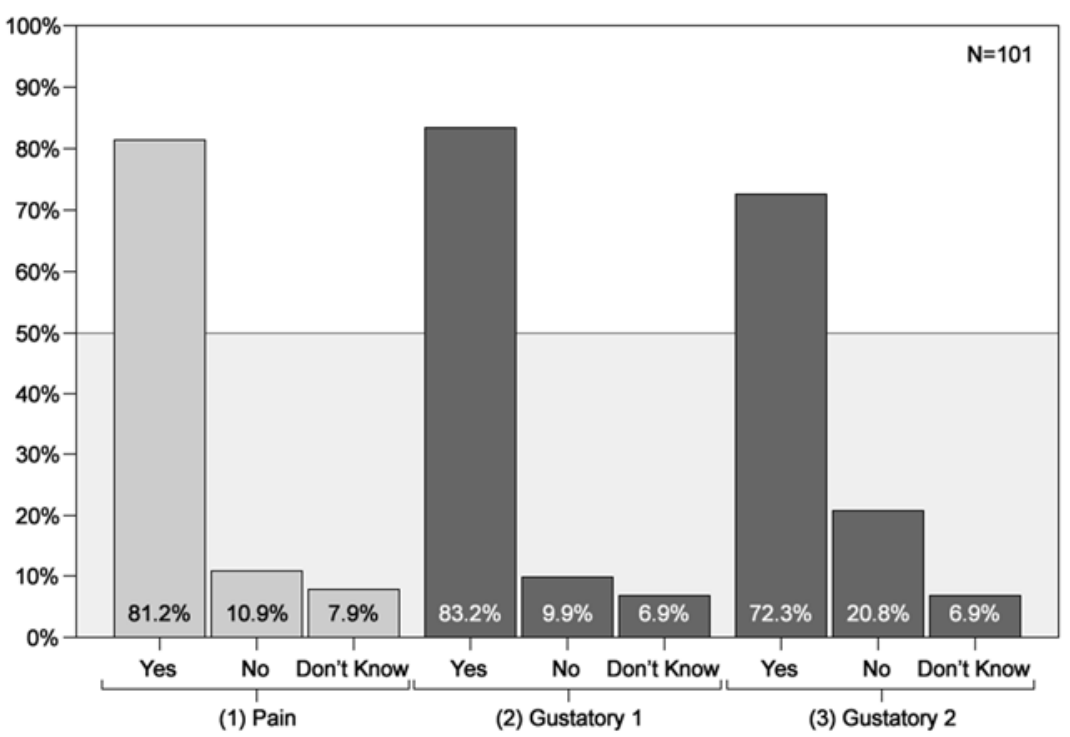

Figure 3: Results for Study 6.

\subsubsection{Studies on Unfelt Pains}

Finally, Reuter and Sytsma (ms) have run a large series of studies that provide further support for the claim that the commonsense conception of pain allows for the occurrence of unfelt pains. For instance, they presented participants with a vignette involving an injured patient taking a painkiller and showing no pain response for a period of time. Unlike the results reported above, this vignette did not involve conjoined twins. The wording for the questions was varied across

\footnotetext{
${ }^{25}$ The percentage of "yes" responses was significantly above $50 \%$ in each case: (1) $\chi^{2}(1, \mathrm{~N}=101)=38.059, \mathrm{p}<0.001$, one-tailed; (2) $\chi^{2}(1, \mathrm{~N}=101)=43.129, \mathrm{p}<0.001$, one-tailed; (3) $\chi^{2}(1, \mathrm{~N}=101)=19.168, \mathrm{p}<0.001$, one-tailed
} 
four studies, in addition to varying whether participants were given a forced-choice or answered using a Likert scale, but in each case Reuter and Sytsma found that a majority of participants responded that the patient had a pain even though she didn't feel it while on the painkiller.

In another set of studies, Reuter and Sytsma presented participants with vignettes involving a soldier who has recently suffered a severe injury but professes to feel no pain, until sometime later when the pain hits him. Echoing the philosophical consensus that the commonsense conception of pain does not allow for unfelt pains, Christopher Hill reports that when he "asked informants to assess the likelihood of this scenario... they have all been inclined to dismiss it as absurd" $(2009,171)$. Reuter and Sytsma found quite the opposite. Across the nine studies they ran, the vignettes were varied between a lengthy description of the phenomenon and a very brief description, in addition to varying whether participants were given a forced-choice or answered using a Likert scale. In each study, however, they found that a majority of participants responded that there was a pain despite the injured soldier not feeling it.

Finally, Reuter and Sytsma asked participants a series of more direct questions including whether all pains are felt and whether a particular pain is felt all of the time. Perhaps most strikingly, in their last two studies they asked the following four questions, with participants either answering by selecting "yes" or "no" or using a 7-point Likert scale:

(1) Is it possible for a person to have a pain that they don't feel for a period of time?

(2) Have you ever had a pain that you didn't feel for a period of time?

(3) Is it possible for a person to have a pain that doesn't hurt for a period of time?

(4) Have you ever had a pain that didn't hurt for a period of time?

In each case a majority of participants gave an affirmative answer. For instance, $92.2 \%$ of participants answered that it is possible for a person to have a pain that they don't feel for a period of time, while $90.2 \%$ of participants answered that they themselves had had a pain that they didn't feel for a period of time! Collectively, these results provide striking new evidence 
that contra the philosophical consensus, the commonsense conception of pain allows for the occurrence of unfelt pains.

\section{Corpus Analysis Studies of the Use of Pain Language}

We have just seen that there is mounting evidence from questionnaire studies suggesting that the commonsense conception of pains diverges from both the standard view in philosophy and what philosophers have assumed about the folk conception. Most notably, while philosophers have argued for the standard view by claiming that commonsense denies the possibility of shared pains, unfelt pains, and pain hallucinations, and asserting that such denials are best explained by the thesis that the folk conception corresponds with the standard view, we saw that by and large lay people accept the possibility of all three.

Another way to investigate the folk conception of pain is to examine the ordinary use of pain language. As noted above, on the standard view there is no appearance-reality distinction to be drawn for pains - to feel a pain is to have a pain and vice versa. Does the same hold for the folk conception? We can test this by analyzing the way people talk about pain. If people do not draw an appearance-reality distinction for pains, then this should show itself in people using phrases like "feeling a pain" and "having a pain" interchangeably. But is this what people actually do?

The most direct means to test whether lay people distinguish the appearance of a pain (feeling a pain) from the reality (having of a pain), would be to systematically listen to people speak about their pains. However, this is difficult to do for at least three reasons: first, it would be very time consuming; second, it would be difficult to gather a representative sample; and, third, even if differences between phrases like "feeling a pain" and "having a pain" were to be 
found, it would need to be shown that these differences arise from people's conceptual distinction between the appearance and the reality of pain.

The first two difficulties can be circumvented by using large linguistic corpora. Linguistic corpora are simply systematic collections of linguistic data—typically drawn from public sources such as newspapers, magazines, and the internet— that can be used for purposes of describing language use and testing hypotheses about languages. ${ }^{26}$ Since health issues are a central aspect of everybody's lives and are talked about frequently in various outlets, data on the usage of pain language is available in existing linguistic corpora.

To avoid the third problem, Reuter (2011) used an analogy with the traditional sense modalities. Most languages, perhaps all languages, allow people to express appearance statements (e.g., "the shirt looks blue") and contrast such statements with factual claims (e.g., "the shirt looks blue but it really is black"). Very often, people's choice of appearance language depends on how certain they feel about a given state of affairs (Quinton 1956, Sellars 1956). If a person feels very confident that the shirt is blue, then the person is more likely make a factual statement such as "the shirt is blue." When they are less confident, however, such as when the lighting conditions are bad, people are more likely to make appearance statements such as "the shirt looks blue." How confident people are about certain external affairs, in turn correlates with the perceived intensity of the property in question. If the shirt is perceived clearly in sunlight, people will be highly certain about what is and what is not the case. In a badly lit room at night, people's confidence suffers from the poor conditions of perception (Lund 1926).

Reuter then argues that while the intensity of certain stimuli has an effect on the use of appearance language, if people do not distinguish between the appearance and the reality of

\footnotetext{
${ }^{26}$ For an introduction to corpus analysis and a discussion of its merits for and applications in philosophical research, see Bluhm (2016).
} 
pains then no such effect should be found for the use of pain language. If, however, it turns out that people tend to state that they have a pain when the intensity of the pain is high, and to state that they feel a pain when the intensity of the pain is low, then this would indicate that they do in fact distinguish the appearance from the reality of pains. To test this, Reuter analyzed eight different pain attributes of the English language—four low-intensity ones (minor, small, slight, little) and four strong ones (severe, major, bad, big). The frequency of each of these attributes in conjunction with pain statements was established by entering phrases like "I feel a severe pain" into various search engines and comparing the number of hits with the contrasting phrase "I have a severe pain." The aim of this method was to examine how strongly the intensity of pain influences people's choice of language. The results show that whereas people use the feeling phrase slightly more often when talking about low-intensity pains, they use the having phrase around three to four times more often when talking about a strong pain. Thus, at least when it comes to English, the results support the hypothesis that the intensity of pain has a decisive effect on whether people assert that they have a pain (factual statement) or feel a pain (appearance statement), indicating that people distinguish the appearance from the reality of pain.

A number of objections are tackled in Reuter (2011). Here we will focus on one objection. It could be argued that the correlation found in the corpus analysis is merely a brute fact about the English language and does not reveal any underlying structure of how people conceive of pain. This objection is easy to test. We can simply repeat the analysis for other languages. Here we begin that process by conducting a similar corpus analysis of the use of pain terms in German. ${ }^{27}$

\footnotetext{
${ }^{27}$ Work on the commonsense conception of pain to date has largely focused on native English-speakers, but see Kim et al. (2016) for a cross-cultural study testing the views of South Koreans.
} 
In order to investigate possible correlations between the choice of certain pain statements and the intensity of a pain stimulus, we entered the following phrases in Google $\odot$, and noted the number of hits for each search—hereafter "I-form":

- „Ich [verb in present tense] einen [adjective] Schmerz“, e.g. „Ich fühle einen großen Schmerz." (English Translation: "I feel a big pain")

- „Ich [verb in past tense] einen [adjective] Schmerz“, e.g. „Ich fühlte einen großen Schmerz." (English Translation: "I felt a big pain")

- „Ich [verb in present tense] [adjective] Schmerzen“, e.g. „Ich fühle große Schmerzen.“ (English Translation: "I feel big pains")

- „Ich [verb in past tense] [adjective] Schmerzen“, e.g. „Ich fühlte große Schmerzen.“ (English Translation: "I feel big pains")

Analogously to English, we used "haben" ("having") for putative factual statements about pain. However, there is no single phrase for the English expression "feeling pain." Instead, German speakers use three different verbs to express that they are feeling pain-Schmerz fühlen, Schmerz spüren, and Schmerz empfinden. Thus, we ran all three of these variants and summed up the results. Three attributes indicating low intensities were used—klein (small), leicht (slight), schwach (weak). Additionally, we looked up uses of the phrases keinen Schmerz haben/fühlen (no pain). Four attributes were used for pains that are of high intensity—groß (big), stark (strong), schlimm (bad), fürchterlich (terrible). ${ }^{28}$

We also investigated phrases like große Schmerzen fühlen (=feeling big pains) and leichte Schmerzen haben (=having slight pains), ${ }^{29}$ which do not connect immediately with a personal pronoun (General Form, see Table 1). The results in Table 1 are comparable to that found by Reuter (2011) for English. With the exception of the phrases for leicht in the I-form, people describe their pains more frequently with feeling language when their pains are of lower

\footnotetext{
${ }^{28}$ While we would have liked to use a larger number of attributes for low-intensity pains, only the four mentioned in the main text yielded a sufficiently high number of hits.

${ }^{29}$ Please note that the plural form "Schmerzen" (=pains) is much more frequently used in German compared to English.
} 
intensities and describe their pains more frequently with having language when their pains are of greater intensities. Interestingly, when looking at the attributes schlimm and fürchterlich, there were hardly any uses of the feeling phrase. To give one example, when entering the phrase "schlimme Schmerzen haben" we got 303 hits in Google. In contrast, the phrase "schlimme Schmerzen spüren" received a mere 25 hits. Given that the attributes small and big are usually considered opposites in most circumstances, we analyzed the results using Pearson's $\chi^{2}$ analysis with factors size (small, big) and phrase (feeling, having). The differences in both the I-form as well as the General Form were highly significant. ${ }^{30}$

\section{Absolute numbers}

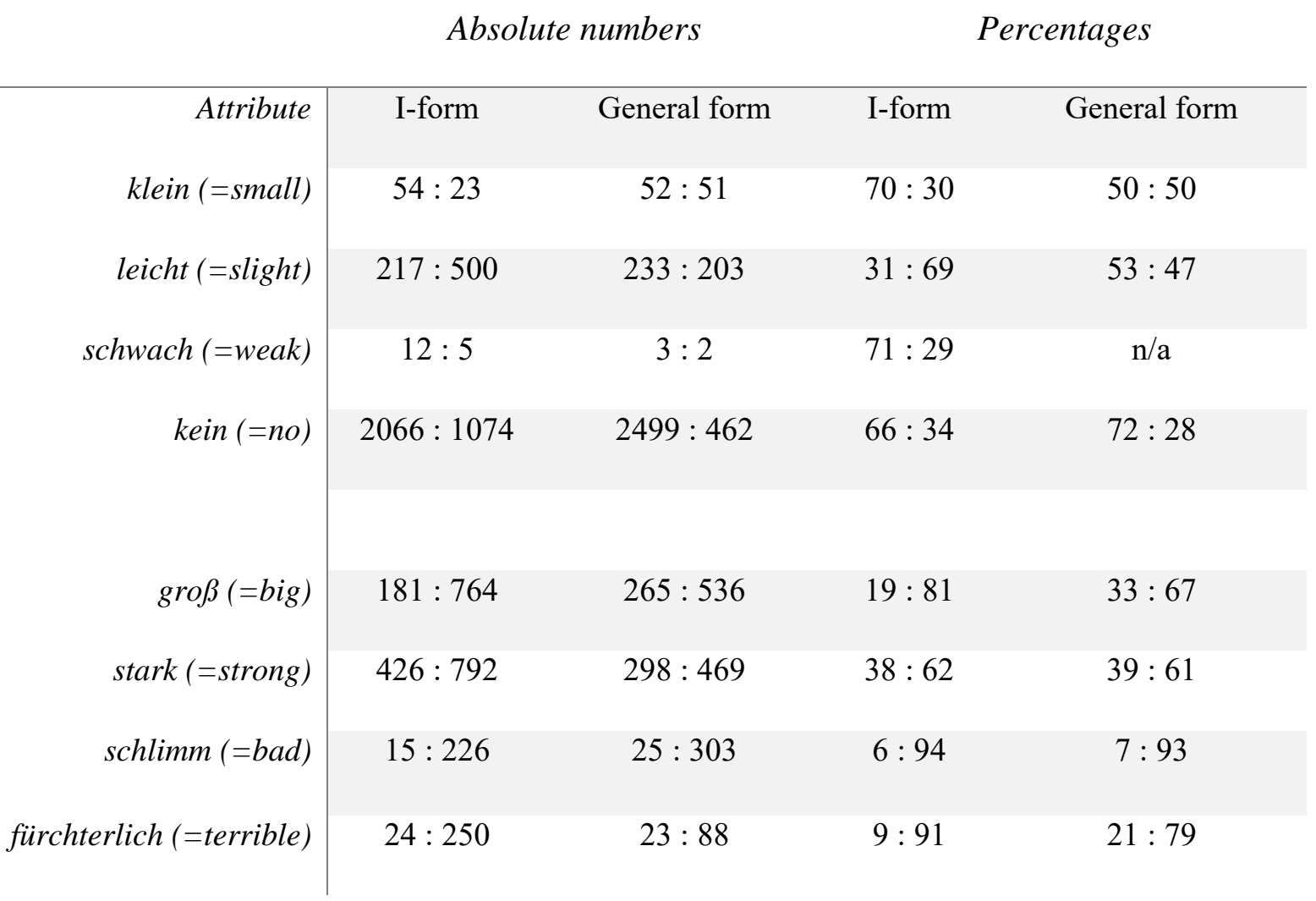

Table 1: Absolute numbers and percentages of all search results using GoogleC. E.g. using the German equivalents for feeling, Google displayed 54 hits for "I feel / felt a small pain" vs. 23 hits for "I have / had a small". Around 70\% of these expressions were hence cast in feeling language.

\footnotetext{
${ }^{30} \mathrm{I}$-form, $\chi^{2}(1, \mathrm{~N}=1019)=103.99, p<0.001$; General Form, $\chi^{2}(1, \mathrm{~N}=904)=12.14, p=0.001$.
} 
The upshot is that the pattern seen in Reuter's original analysis does not appear to simply reflect a brute fact about English, but is also found in German. While further work is needed to extend this to additional languages, it is unlikely that these twin findings are mere coincidence, providing additional support for the claim that pain admits an appearance-reality distinction and, thus, that the standard view of pain in philosophy is mistaken.

\section{Conclusion}

The standard view amongst philosophers today is that pains are phenomenally conscious mental states. This view is generally supported by appeal to the commonsense conception of pains. And, yet, a growing body of evidence from experimental philosophers indicates that the commonsense conception of pains is much different than philosophers have assumed, diverging significantly from the standard view. In this paper, we have both surveyed this literature and contributed to it, detailing the results of seven new studies on the commonsense conception of pain as well as the use of pain language. The accumulated research suggests that people tend to conceive of pains not as mental states, but as bodily states, while allowing for the occurrence of shared pains, unfelt pains, and pain hallucinations.

\section{References}

Alexander, Joshua (2012). Experimental Philosophy: An Introduction. Cambridge: Polity Press. Aydede, Murat (2005a). "Preface," in Pain: New Papers on its Nature and the Methodology of its Study, M. Aydede (ed.), Cambridge, MA: MIT Press: ix-xvii.

Aydede, Murat (2005b). "Introduction: A critical and quasi-historical essay on theories of pain," in Pain: New Papers on its Nature and the Methodology of its Study, M. Aydede (ed.), Cambridge, MA: MIT Press: 1-58.

Aydede, M. (2009). "Pain," in The Stanford Encyclopedia of Philosophy 
(Spring 2013 Edition), ed. E. Zalta, http://plato.stanford.edu/archives/spr2013/entries/pain/ Bock, Ned (2005). "Bodily Sensations as an Obstacle for Representationism," in Pain: New Papers on Its Nature and the Methodology of Its Study, M. Aydede (ed.), pp. 137-142. Cambridge, MA: MIT Press.

Bluhm, Roland (2015). "Corpus Analysis in Philosophy," in Evidence, Experiment and Argument in Linguistics and the Philosophy of Language, M. Hinton (ed.), Peter Lang: 91-109.

Knobe, Joshua and Shaun Nichols (2008). Experimental Philosophy. New York: Oxford University Press.

Knobe, Joshua and Shaun Nichols (2013). Experimental Philosophy, Volume 2. New York: Oxford University Press.

Hill, Christopher (2009). Consciousness, Cambridge: Cambridge University Press.

Kim, Hyo-eun, Nina Poth, Kevin Reuter, and Justin Sytsma (2016). "Where is your pain? A Crosscultural Comparison of the Concept of Pain in Americans and South Koreans," Studia Philosophica Estonica, 9(1): 136-169.

Knobe, Joshua and Jesse Prinz (2008). "Intuitions about Consciousness: Experimental Studies," Phenomenology and the Cognitive Sciences, 7: 67-83.

Lewis, David (1980). "Mad Pain and Martian Pain," in Readings in the Philosophy of Psychology, N. Block (ed.), pp. 216-222. Cambridge, MA: Harvard University Press.

Lund, F. H. (1926). “The Criteria of Confidence,” The American Journal of Psychology, 37(3), $372-381$.

Machery, Edouard and Elizabeth O’Neill (eds.), Current Controversies in Experimental Philosophy, New York: Routledge.

Machery, Edouard and Justin Sytsma (2011). "Robot Pains and Corporate Feelings.” The Philosophers’ Magazine, 1st Quarter: 78-82.

Nagel, Thomas (1974). "What is it like to be a bat?" The Philosophical Review, 83: 435-450.

Putnam, Hilary (1963). "Brains and Behavior," in Analytic Philosophy ( $2^{\text {nd }}$ Series), R. J. Butler (ed.), Oxford: Basil Blackwell, pp. 211-235.

Quinton, A. M. (1956). “The Problem of Perception.” Mind, 64: 28-51.

Reuter, Kevin (2011). "Distinguishing the appearance from the reality of pain." Journal of Consciousness Studies, 18(9-10): 94-109.

Reuter, Kevin (2016). “The Developmental Challenge to the Paradox of Pain.” Erkenntnis. 
Reuter, Kevin, Dustin Phillips, and Justin Sytsma (2014). "Hallucinating Pain," in Advances in Experimental Philosophy of Mind, J. Sytsma (ed.), London: Bloomsbury.

Reuter, Kevin and Justin Sytsma (ms). "Unfelt Pain."

Sellars, Wilfrid (1956). Empiricism and the Philosophy of Mind. Cambridge, MA: Harvard University Press.

Sytsma, Justin (2009). "Phenomenological Obviousness and the New Science of Consciousness," Philosophy of Science, 76(5): 958-969.

Sytsma, Justin (2010a). "Folk Psychology and Phenomenal Consciousness," Philosophy Compass, 5(8): 700-711.

Sytsma, Justin (2010b). "Dennett's Theory of the Folk Theory of Consciousness," Journal of Consciousness Studies, 17(3-4): 107-130.

Sytsma, Justin (2010c). Phenomenal Consciousness as Scientific Phenomenon? A Critical Investigation of the New Science of Consciousness. Ph.D. Dissertation. Pittsburgh, PA: University of Pittsburgh.

Sytsma, Justin (2012). "Revisiting the Valence Account," Philosophical Topics, 40(2): 179-198.

Sytsma, Justin (2014a). “Attributions of Consciousness,” WIREs Cognitive Science, 5: 635-648.

Sytsma, Justin (2014b). Advances in Experimental Philosophy of Mind, London: Bloomsbury.

Sytsma, Justin (2014c). "The Robots of the Dawn of Experimental Philosophy of Mind," in Current Controversies in Experimental Philosophy, E. Machery and E. O’Neill (eds.), New York: Routledge.

Sytsma, Justin (forthcoming). "Two Origin Stories for Experimental Philosophy," teorema.

Sytsma, Justin and Wesley Buckwalter (2016). A Companion to Experimental Philosophy, Oxford: Blackwell.

Sytsma, Justin and Jonathan Livengood (2015). The Theory and Practice of Experimental Philosophy. Broadview.

Sytsma, Justin and Edouard Machery (2009). "How to Study Folk Intuitions about Phenomenal Consciousness," Philosophical Psychology, 22: 21-35.

Sytsma, Justin and Edouard Machery (2010). "Two Conceptions of Subjective Experience," Philosophical Studies, 151(2): 299-327. 
Sytsma, Justin and Edouard Machery (2012). "On the Relevance of Folk Intuitions: A Reply to Talbot," Consciousness and Cognition, 21(2): 654-660.

Sytsma, Justin and Edouard Machery (2013). "Experimental Philosophy," in Encyclopedia of Philosophy and the Social Sciences, B. Kaldis (ed.), pp. 318-320. Thousand Oaks, CA: SAGE.

Tye, Michael (2005). "Another Look at Representationalism about Pain," in Pain: New Papers on Its Nature and the Methodology of Its Study, M. Aydede (ed.), pp. 99-120. Cambridge, MA: MIT Press. 